\title{
Knock Detection in Piston Engines
}

\author{
Pedro Dias ${ }^{1}$ and Francisco Brójo ${ }^{2, *}$ \\ ${ }^{1}$ Department of Aeronautic Sciences, University of Beira Interior, Portugal, pedro_park7@hotmail.com \\ ${ }^{2}$ C-MAST, Department of Aeronautic Sciences, University of Beira Interior, Portugal, brojo@ubi.pt \\ *Corresponding author
}

\begin{abstract}
The present work had as main objectives to detect and analyse detonation vibration patterns and evaluate which ignition angle should be used for each angular velocity on the used engine
\end{abstract}

\section{Keywords-knock; ignition angle; vibration; piston engine}

\section{INTRODUCTION}

Thermal engines are a social pillar by their contribution for the improvement of life quality. Society impact by the internal combustion engines extends for several centuries until the present day [1]. Although the internal combustion engines have been implemented in the beginning of sec. XIX, studies to increase working knowledge and consequently allow performance improvement are still done today.

Operation of a piston engine is divided in four phases: admission, compression, expansion and exhaust. Phases can happen sequentially (4 stroke engine) or grouped (2 stroke engine). The most important stroke to the operation of the engine is the combustion process (this process starts close to the the end of the compression stroke and extends to the expansion stroke). It is at this stage that the fuel mixture with the oxidant burns, producing work. Temperature and pressure of the working fluid inside engine reach during this process the highest values.

The performance of the combustion process change along the useful life of the engine, depending from several factors (e.g., working hours, engine maintenance, type of fuel used and load).

Sensors are used by manufacturers to monitor working parameters and guarantee higher operational efficiencies and safe use of the engine. These sensors allow correction of operation parameters by collection of working data to be processed by engine Electronic Unit (ECU), which in turn send orders to actuators, to control the engine, preventing certain phenomenon to happen and allowing this way to improve the performance of the engine.

Parameters measured by engine sensors are: pressure, temperature, humidity, exhaust gases oxygen content, velocity and knock, amongst others.

To maximize net work produced by an engine, the pressure inside the cylinder must attain the highest value possible. Ignition angle is a very important parameter in what concerns pressure. If the ignition angle is the correct one, maximum pressure will occur slightly after piston top dead center. If ignition angle is to retarded, pressure inside cylinder never attain the highest value and if ignition angle is to advanced, pressure inside cylinder might rise too much and temperature could reach fuel self-ignition temperature, causing abnormal combustion. Combustion behavior is dependent on the fuel self-ignition temperature and ignition delay. These parameters, even for the same air-fuel mixture are uncertain and depend on temperature, pressure, density, turbulence, swirl, fuel-air ratio and exhaust gases content, between others, which turns the task of optimizing the ignition angle advance a difficult one. Care must be taken and the chosen ignition angle advance is therefore decided with engine safety in mind, leading to less energy extracted from fuel.

Abnormal combustion can manifest itself by noise and in certain conditions damages the engine. In spark ignition engines, combustion can start by the spark, by surface ignition at a combustion chamber hot point and by high pressures and temperatures at the fresh mixture before the flame front arrives. The last one is associated with what is usually known as detonation or knock.

Detonation is a phenomenon of an abnormal combustion that can cause damage to the engine. To severe damage prevents the engine from functioning [2]. Abnormal combustion usually happen soon after the mixture is ignited. Flame speed is in this case superior to the one present in other types of abnormal combustion, leading to the production of sharp pulses of pressure associated to mechanical vibratory moment and a characteristic metallic sound, called "knock" [3].

One way to detect detonation in an engine is to use a knock sensor (see Figure I). This type of sensor detects vibrations generated during engine operation.

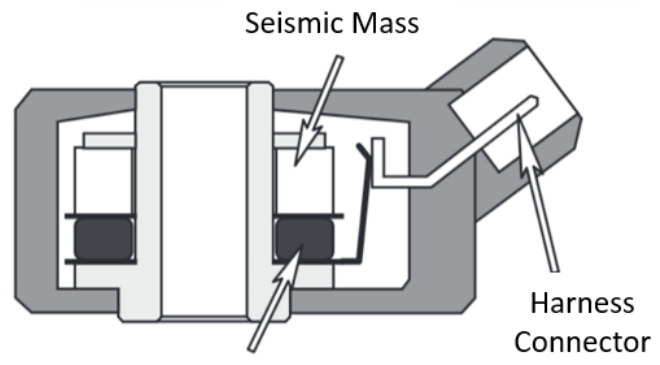

Piezo-electric Ceramic

FIGURE I. EXAMPLE OF KNOCK SENSOR [4]

The knock sensor should be placed very close to the engine cylinder, tightened with the torque indicated by the manufacturer and connected to the ECU by a shielded cable in order to eliminate electromagnetic interference. 
In Figure II, signals $a, b$ and $c$ represent respectively, the electrical signal collected by the pressure sensor inside the combustion chamber, the knock sensor signal without knock and the signal with knock. On the left signal is filtered.
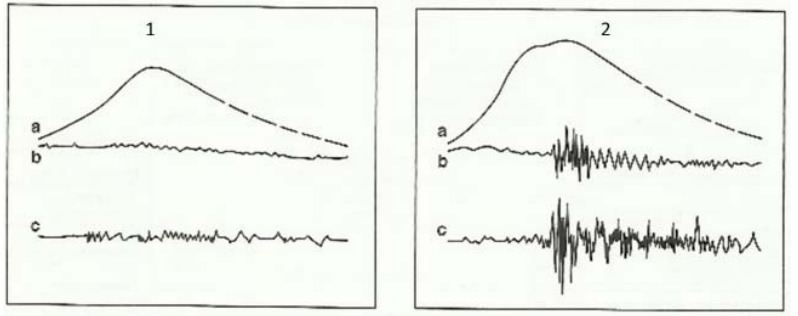

FIGURE II. SIGNAL CAPTURED BY A KNOCK SENSOR [5]

\section{EXPERIMENTAL SETUP}

Experimental work was performed at the Energetic and Thermal Engines Laboratory of the Department of Electromechanical Engineering of University of Beira Interior. The engine used was a HONDA GX 120, modified to use a Haltech E6H electronic injection and ignition controller [6, 7]. Working cycle for this engine is 4-stroke spark ignition. Table I presents principal working parameters of stock engine.

TABLE I. HONDA GX 120 PARAMETERS[6]

\begin{tabular}{|l|c|}
\hline \multicolumn{1}{|c|}{ Table Head } & Table Column Head \\
\hline Number of cylinders & 1 \\
\hline Displaced volume $\left[\mathrm{cm}^{3}\right]$ & 118 \\
\hline Stroke [mm] & 42 \\
\hline Bore [mm] & 60 \\
\hline Compression ratio & $8.5: 1$ \\
\hline Maximum power (at 3500 rpm) [kW] & 2.5 \\
\hline Maximum torque (at 2500 rpm) [N.m] & 7.3 \\
\hline Empty Weight [kg] & 13 \\
\hline
\end{tabular}

Knock sensor used, was SKU 041848 (see Figure III). Its installation is very important since affects signal quality.

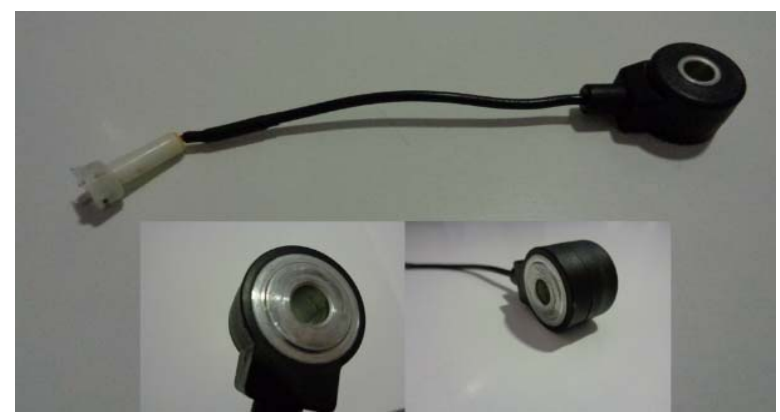

FIGURE III. KNOCK SENSOR SKU 041848

Experimental rig is shown in Figure IV, with engine on the left, computed connected to ECU at middle and computer controlling signal acquisition at the right.

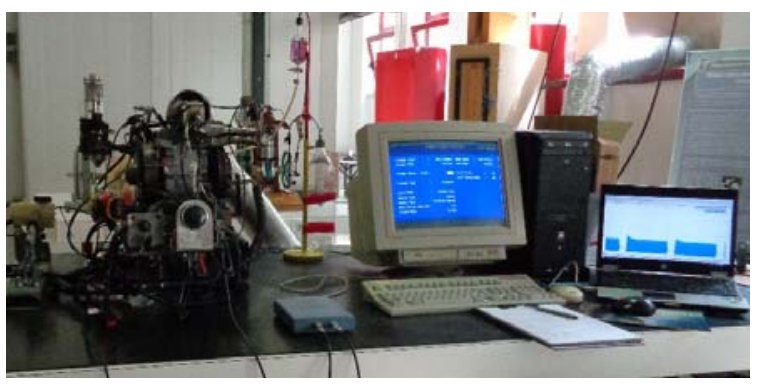

FIGURE IV. EXPERIMENTAL RIG

Fuel used was commercial available petrol with 95 octanes number. Constant load was applied to the engine using a mechanical brake, limiting engine operation to a maximum of 3000 rpm.

Ignition signals were acquired with a PicoScope 6 Automotive oscilloscope [8]. Ignition trigger signal (red, Figure V) was compared with stock magnet trigger signal (blue, Figure V) to determine exactly the ignition angle for the ECU. This way position of top and bottom dead centers were known.

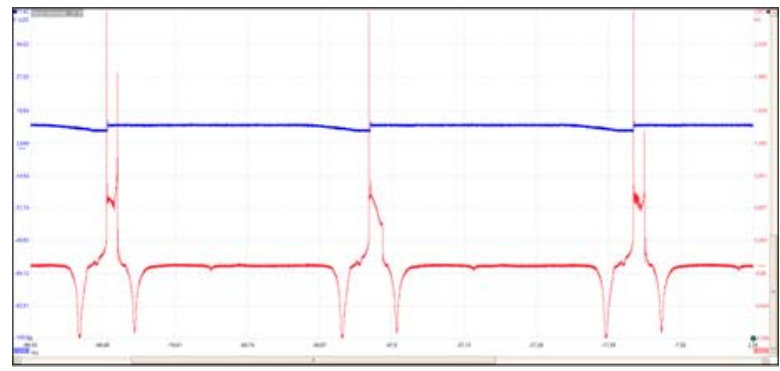

FIGURE V. SPARK IGNITION MEASURED SIGNALS

To know trigger signal angle also allow to know valves actuation times as marked in Figure VI [9]. Red color braces identify vibration amplitude. Legend shows "DELTA V Cycle" and "DELTA V Window", green color corresponds the engine cycle of operation and combustion window was set according to reference [10]. There were also used guides to mark exhaust and intake valves actuation times. These guides have the captions EVC, AVC, EVO and AVO. In the lower section of Figure VI, brown guides mark position of the spark throughout an engine operating cycle.

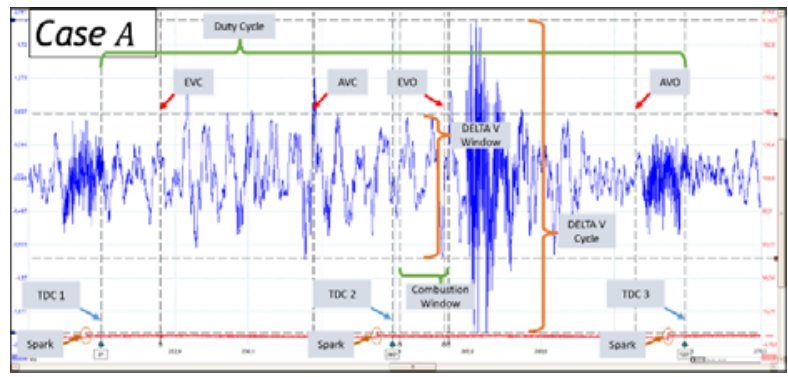

FIGURE VI. ENGINE EVENTS

\section{RESUlTS}

Experimental measurements were made with the engine at working temperature and starting from higher velocity to the lower one. Two runs were made for ignition angles used $\left(10^{\circ}\right.$, 
$20^{\circ}, 30^{\circ}, 40^{\circ}, 50^{\circ}, 60^{\circ}, 70^{\circ}$ and $75^{\circ}$ ) for constant load and starting from wide open throttle (WOT) to fully closed throttle.

For ignition angles of $75^{\circ}$ and $70^{\circ}$ the engine turned off abruptly as result of severe knock.

Figure VII presents results for an ignition angle of $60^{\circ}$. Case A has a recorded velocity of $2727 \mathrm{rpm}$. For this case the vibrations are the highest. Vibration amplitude reduces with the reduction of velocity. Case D, with a recorded velocity of 2135 rpm has the combustion vibration slightly before the recommended combustion window [10]. Case $\mathrm{H}$ is at a recorded velocity of $673 \mathrm{rpm}$. In this case changes in vibration pattern suggest that knock is already present. Nevertheless, it is not strong enough to stop the engine.

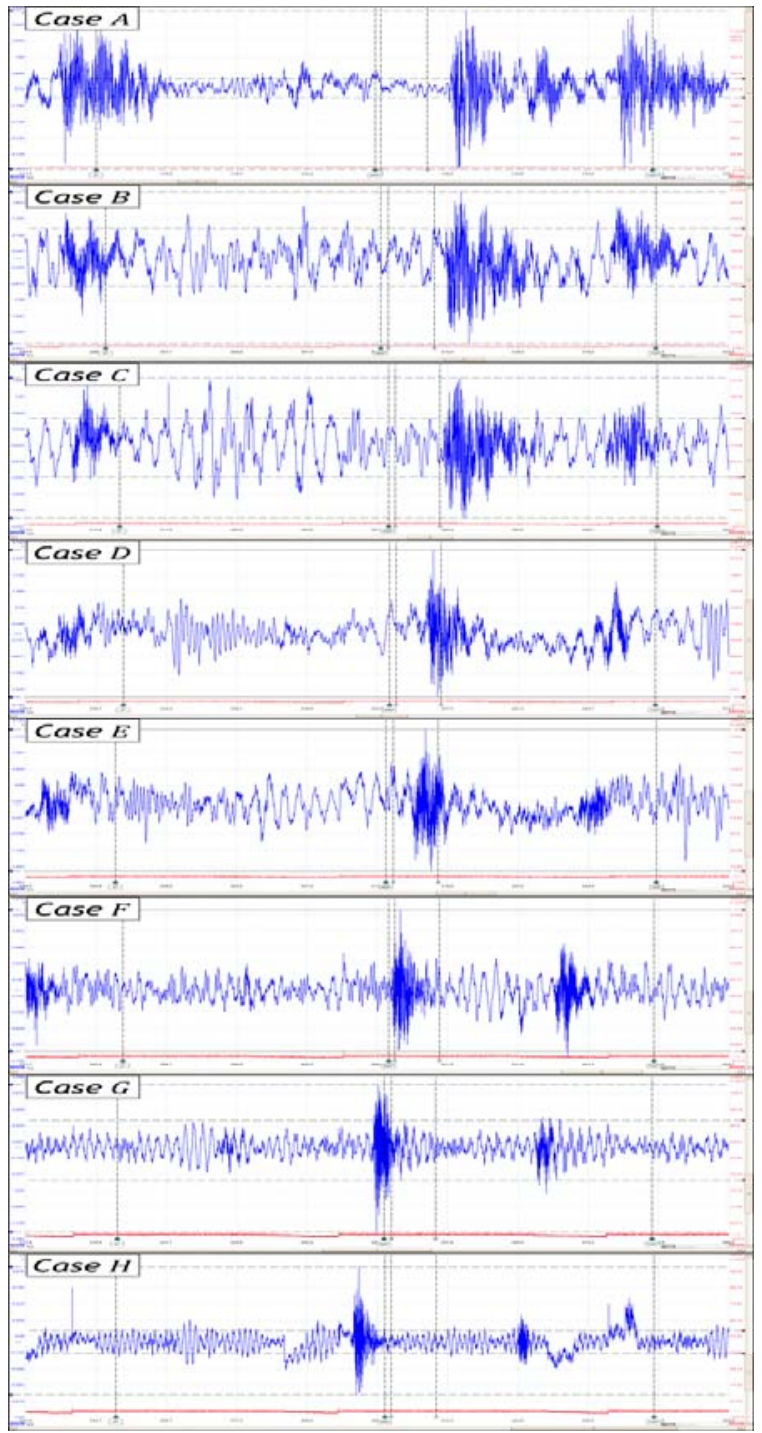

FIGURE VII. TESTS RUN WITH IA OF $60^{\circ}$. VELOCITIES FROM TOP TO BOTTOM ARE 2727, 2632, 2469, 2135, 1840, 1395, 1029 AND 673 RPM

For tests with an ignition angle of $10^{\circ}$ (Fig. VIII) can be seen that the amplitude of each case vibration has approximately the same value, even for higher angular velocities. When the rotational velocity of the engine reaches the lowest value the corresponding combustion vibration is already inside in the combustion window. Opposite from what is seen in Figure VII changes in pattern behavior are not visible. For this ignition angle, the combustion vibration never occurs before the piston top dead center, making knock difficult to occur. Nevertheless, hot spots inside the engine might promote knock, even in the present conditions.

A second analysis was performed considering constant velocity for the engine and changing the ignition angle. Results for a velocity of approximately $700 \mathrm{rpm}$ are presented at Figure IX.

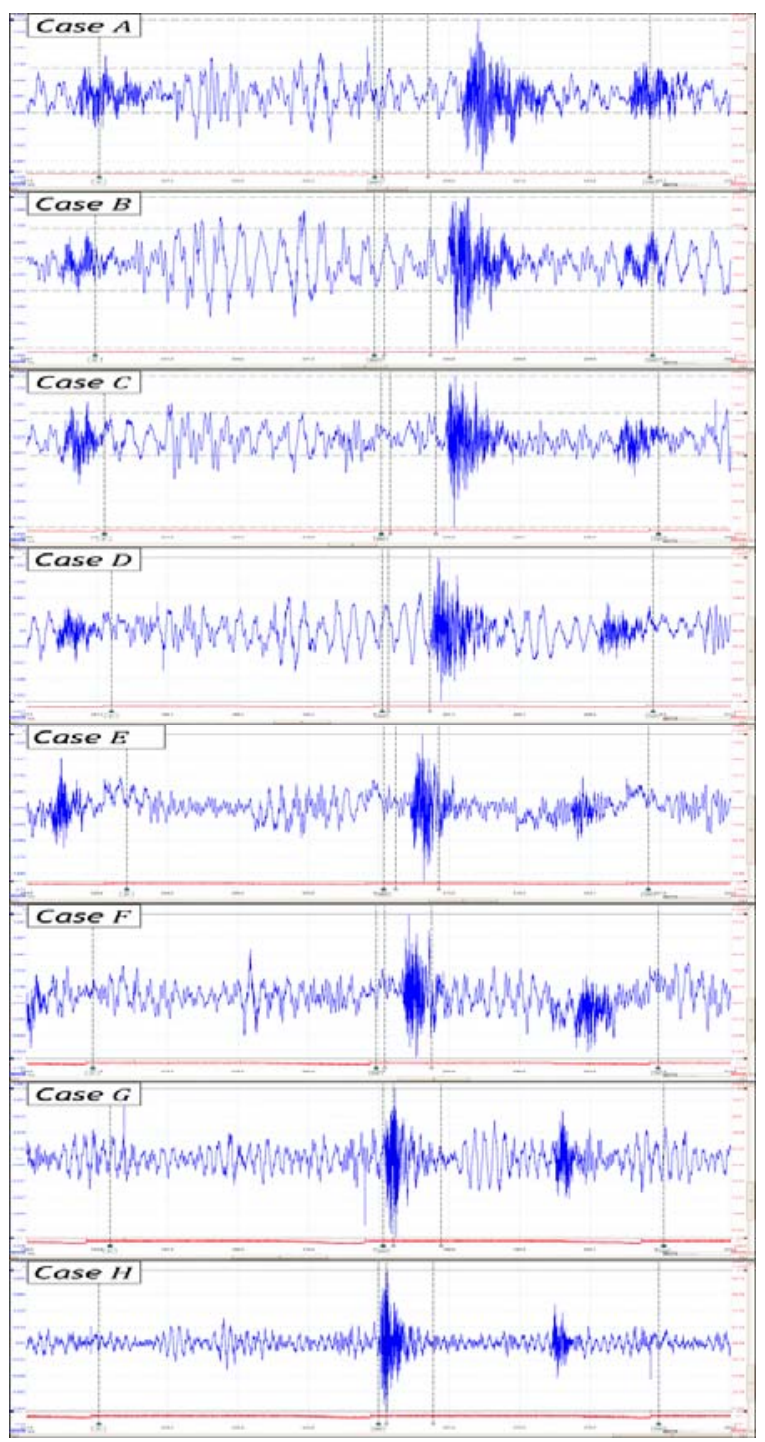

FIGURE VIII. TESTS RUN WITH IA OF $10^{\circ}$. VELOCITIES FROM TOP TO BOTTOM ARE 2632, 2400, 2214, 1948, 1690, 1485, 1130 AND 904 RPM.

Case A is for 904 rpm, Case B for 670 rpm, Case C for 638 rpm, Case D for $656 \mathrm{rpm}$, Case E for $673 \mathrm{rpm}$ and Case F for $673 \mathrm{rpm}$. With the exception of case A, combustion pattern is always before piston top dead center. With the exception of Case $\mathrm{F}$, where there is clearly a vibration pattern change, there 
is no indication of knock. However, other factors can influence knock.

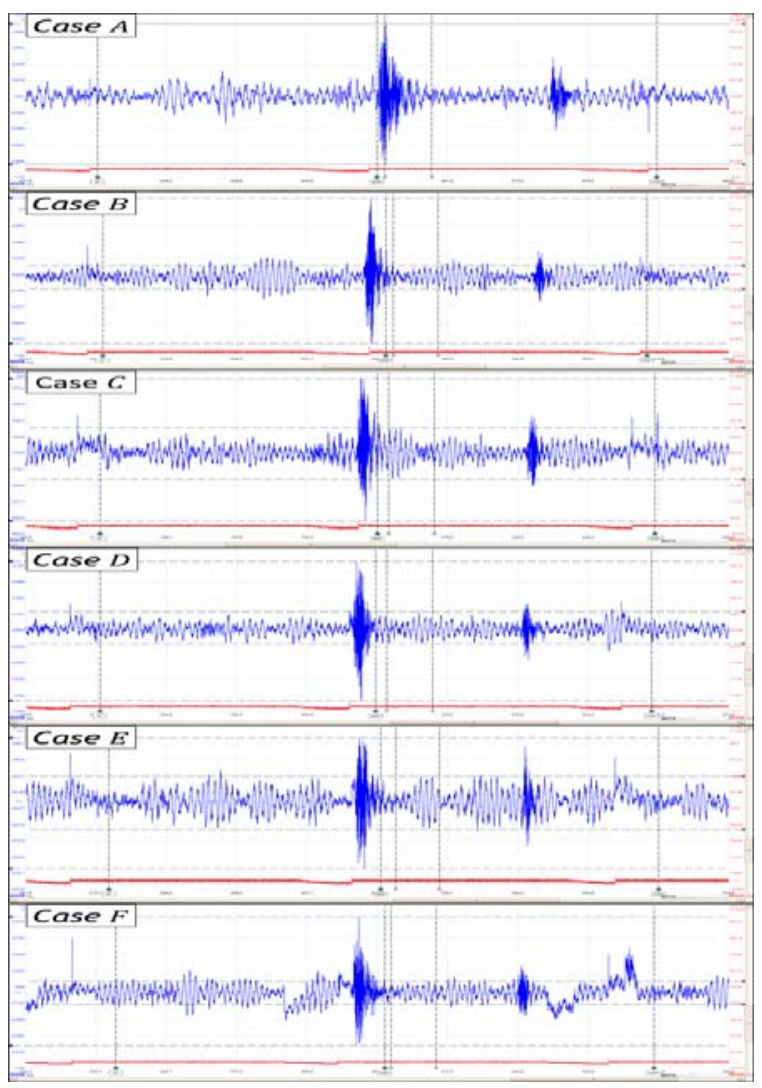

FIGURE IX. TESTS RUN WITH ENGINE VELOCITY OF 700 RPM. IGNITION ANGLES FROM TOP TO BOTTOM ARE $10^{\circ}, 20^{\circ}, 30^{\circ}$, $40^{\circ}, 50^{\circ}, 60^{\circ}$

Figure $\mathrm{X}$ presents values for recommended maximum ignition angle as function of engine velocity. For construction of this graph combustion window usual angles [10] were used. Use of ignition angles higher than the presented ones lead to pressure peak before the piston top dead center and might produce engine knock. Best data fitting is with a power curve with a coefficient of determination of 0,8932 .

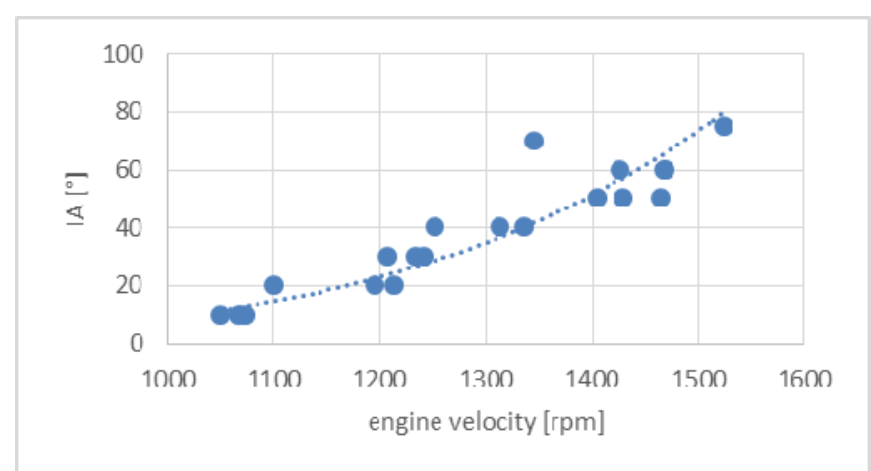

FIGURE X. IGNITION ANGLE AS FUNCTION OF ENGINE VELOCITY [RPM]

\section{CONCLUSIONS}

Using a simple knock sensor is possible to determine combustion vibration position. With that knowledge is possible to calculate correct ignition angle for useful range of engine velocities.

With the increase of the ignition angle, the minimum engine velocity change is smaller, meaning that the knock risk increases steeply.

\section{REFERENCES}

[1] Martins, J., “Motores de Combustão Interna”, Publindústria - Edições Técnicas, 2005.

[2] Heywood, J. B., “Internal Combustion Engine Fundamentals”, McGraw-Hill, Inc, 1988.

[3] Puzinauskas, P. V., "Examination of Methods used to Characterize Engine Knock”, SAE Technical Paper Series, Paper Nº. 920808, Detroit, Michigan, 2002.

[4] Catalog, “Test Thomson", MTE-Thomson, page 10

[5] BOSCH, "Gasoline-engine management", Robert Bosch GmbH, $1^{\text {st }}$ Edition, SAE Society of Automotive Engineers, September 1999.

[6] Honda, “Owner's Manual GX 120/160/200”.

[7] Haltech - Engine Management Systems, "Haltech E6H/E6M Manual”.

[8] Pico Technology, "PicoScope 6 - PC Oscilloscope Software User's Guide”.

[9] Navio, F., "Previsão do desempenho de motores alternativos com ignição por faísca”, University of Beira Interior, Covilhã - Portugal, October 2011, (MSc Dissertation).

[10] Horner, J.B., “Engine Knock Detection Using Spectral Analysis Techniques With a TMS320 DSP", Texas Instruments Application Report SPRA039, U.S.A., 1995. 